УДК 616.71-007.234(571.54)

DOI: 10.18101/2306-1995-2019-2-10-17

\title{
ВИТАМИН D КАК ФАКТОР РИСКА ОСТЕОПОРОЗА У НАСЕЛЕНИЯ РЕСПУБЛИКИ БУРЯТИЯ
}

\author{
(C) Батудаева Татьяна Ивановна \\ кандидат медицинских наук, доцент, заведующая кафедрой терапии, \\ Бурятский государственный университет им. Д. Банзарова \\ Россия, 670002, г. Улан-Удэ, ул. Октябрьская, 36а \\ E-mail: batudaeva@gmail.com

\section{(C) Санжиева Дулма Зориктуевна} \\ врач клинико-диагностической лаборатории, \\ Республиканская клиническая больница им. Н. А. Семашко \\ Россия, 670047, г. Улан-Удэ, ул. Павлова, 12 \\ E-mail: sanzhieva.dulma@yandexl.ru
}

Нами исследован уровень витамина 25(OH)D в сыворотке крови 1323 пациентов, проживающих в Республике Бурятия и проведен сравнительный анализ содержания витамина D в зависимости от пола и расовой принадлежности. Средняя концентрация витамина D в сыворотке крови у мужчин оказалась

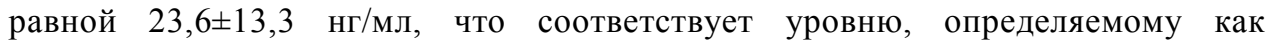
недостаточность витамина D. У женщин средний уровень витамина D в сыворотке крови оказался соответствующим показателю дефицита и составил $18,6 \pm 9,8$ нг/мл. При дальнейшем анализе среднего содержания витамина D в сыворотке крови у лиц разной расовой принадлежности выявлено, что мужчины и женщины азиатской расы имеют достоверно более низкие показатели витамина $\mathrm{D}$ по сравнению с пациентами европеоидной расы, независимо от пола - для мужчин-азиат средняя концентрация витамина D составила $21,6 \pm 12,7$ нг/мл по

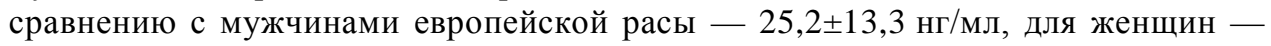
$16,6 \pm 9,1$ нг/мл и 19,6 $\pm 9,9$ нг/мл, соответственно $(\mathrm{p}<0,01)$.

Ключевые слова: остеопороз, факторы риска, остеопорозные переломы, витамин D.

Для цитирования:

Батудаева Т. И., Санжиева Д. 3. Витамин D как фактор риска остеопороза у населения Республики Бурятия // Вестник Бурятского государственного университета. Медицина и фармация. 2019. Вып. 2. С. 10-17.

Остеопороз (ОП) является хроническим системным поражением скелета, характеризующимся снижением массы костной ткани и нарушением ее качества, что приводит к повышению хрупкости кости и переломам. Переломы костей при остеопорозе происходят при минимальной травме - падении с высоты собственного роста или спонтанно. Хотя остеопороз является системным поражением скелета и может приводить к переломам костей любой локализации, наиболее частыми и типичными являются переломы тел позвонков, дистального отдела предплечья, проксимального отдела бедра (чрезвертельные и подвертельные переломы), проксимального отдела плечевой кости. 
T. И. Батудаева, Д. 3. Санжиева. Витамин D как фактор риска остеопороза у населения Республики Бурятия

Эксперты Международного Фонда Остеопороза (International Osteoporosis Foundation - IOF) отмечают, что каждые три секунды в мире происходит один перелом, вызванный остеопорозом; начиная с возраста 50 лет одна из трех женщин и один из пяти мужчин в течение оставшейся жизни перенесут хотя бы один перелом, связанный с остеопорозом [6]. Также известно, что у женщин риск перелома шейки бедра превышает суммарный риск рака молочной железы, яичников и матки; у мужчин риск перелома превышает риск рака предстательной железы. Примерно у 50\% людей, перенесших один остеопорозный перелом, в будущем случится второй перелом, и с каждым новым переломом риск последующих растет в геометрической прогрессии [6].

Проблема остеопороза и его осложнений не является сугубо медицинской, общество несет и огромные экономические потери. Так, за 2010 г. в 27 странах Европейского Союза на лечение пациентов, перенесших малотравматичные переломы, было потрачено 37 миллиардов евро, по оценке специалистов, к 2025 г. эта сумма увеличится на 25\% [13]. В нашей стране затраты на лечение основных остеопорозных переломов могут достигать 25 млрд руб. в год [5].

Как отмечают специалисты IOF, переломы при минимальной травме не являются обязательными для пожилых людей и стариков, в настоящее время имеются все возможности для ранней диагностики остеопороза и своевременной профилактики заболевания, а также лекарственные препараты, способные изменить течение болезни, уменьшить риски развития переломов костей у лиц старшей возрастной группы, улучшить прогноз не только в отношении качества жизни пожилых пациентов, но и увеличить продолжительность жизни людей, страдающих остеопорозом.

Факторы риска остеопороза хорошо известны и изучены. Знание их необходимо, в первую очередь, участковому терапевту или врачу общей практики для формирования групп риска развития остеопороза и своевременного направления пациентов на обследование с целью диагностики заболевания и назначения профилактических или лечебных мероприятий лицам, нуждающимся в них. Согласно клиническим рекомендациям по остеопорозу 2012 г. [8] выделены следующие факторы риска остеопороза и переломов:

- возраст старше 65 лет;

- женский пол (соотношение женщины: мужчины составляет 3:1);

- европеоидная раса;

- предшествующие переломы при небольшой травме;

- склонность к падениям;

- низкая минеральная плотность кости (МПК);

- наследственность (семейный анамнез по переломам проксимального отдела бедренной кости);

- системный прием глюкокортикостероидов более 3 мес.; 
- низкая физическая активность;

- длительная иммобилизация;

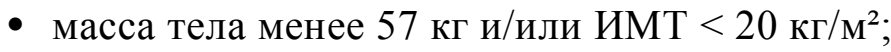

- гипогонадизм у мужчин и женщин;

- курение и злоупотребление алкоголем;

- недостаточное потребление кальция;

- дефицит витамина D;

- снижение клиренса креатинина и/или клубочковой фильтрации.

Необходимо, однако, отметить, что в последних Федеральных клинических рекомендациях по диагностике, лечению и профилактике остеопороза 2017 г. приводятся лишь факторы риска остеопороза, включенные Всемирной Организацией Здравоохранения в модель расчета вероятности переломов в ближайшие 10 лет (т. н. инструмент FRAX) [9], к которым относятся:

- возраст;

- пол;

- предшествующие остеопорозные переломы;

- низкая МПК в области шейки бедра;

- низкий индекс массы тела;

- прием глюкокортикостероидов внутрь $\geq 5$ мг (в расчете на преднизолон) в течение более 3 мес.;

- наличие у пациента ревматоидного артрита;

- наличие других заболеваний, вызывающих вторичный остеопороз;

- перелом бедра у родителей в анамнезе;

- курение (на момент опроса);

- прием алкоголя (3 порции в сутки и более).

Ранее, в группе женщин 50 лет и старше, проживающих в Бурятии и имеющих минеральную плотность костной ткани, соответствующую диагнозу остеопороза, нами были выявлены такие факторы риска

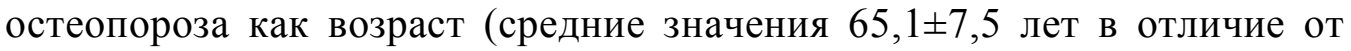
группы женщин с нормальными показателями МПК - 56,9 6,0 лет), более низкие показатели массы тела и индекса массы тела $(63,4 \pm 9,7$ кг против 76,6 $\pm 12,2$ кг в группе женщин не страдающих остеопорозом; $25,2 \pm 3,7$ против $29,4 \pm 4,3$ соответственно) и более поздний возраст начала менструального цикла $(14,3 \pm 1,5$ года у пациенток с остеопорозом против $13,6 \pm 1,4$ года у женщин с нормальными показателями костной массы) [2]. Наряду с перечисленными был выявлен факт достоверно большего количества остеопорозных переломов различных локализаций в анамнезе у пациенток с низкой минеральной плотностью костной ткани по сравнению с женщинами, имеющими нормальные показатели МПК. Все перечисленные значения имели статистическую достоверность различий. Также согласно 
T. И. Батудаева, Д. 3. Санжиева. Витамин D как фактор риска остеопороза у населения Республики Бурятия

полученным нами данным, остеопорозные переломы случаются у женщин, проживающих в нашей республике, в 2,4 раза чаще, чем у мужчин [1]. Различия между полученными нами данными и результатами эпидемиологических исследований в других регионах России, вероятно, обусловлены тем, что в наших работах не учтены переломы тел позвонков в связи с определенными трудностями при диагностике, в частности, пациенты, перенесшие остеопорозные переломы тел позвонков, нередко не обращаются за помощью в лечебное учреждение или им не проводится рентгенологическое исследование.

При дальнейшем анализе осложнений остеопороза у жителей Бурятии нами выявлено, что лица коренной национальности имеют низкоэнергетические переломы в 2 раза чаще, чем жители славянской национальности [3]. Так, среди бурят частота остеопорозных переломов составила 648,8 случая на 100000 человек, среди русских - 323,6 случая на 100000 жителей соответственно.

В связи с выявлением значительной разницы в частоте распространенности остеопорозных переломов у лиц разных этнических групп нами предпринято исследование содержания витамина D в сыворотке крови лиц, проживающих в Республике Бурятия, поскольку факт влияния витамина D на метаболизм костной ткани хорошо известен. Согласно данным систематических обзоров литературы, дефицит витамина D в сыворотке крови ассоциируется с повышением риска развития остеопороза и связанных с ним переломов костей, а также увеличивает риск падений, мышечной слабости, общей и сердечно-сосудистой смертности [12].

Проведенные в нескольких городах России исследования распространенности дефицита витамина D подтвердили наличие его в разных популяционных группах. Так, снижение уровня витамина D ниже нормы выявлено у 89\% женщин в возрасте от 25 до 56 лет, проживающих в г. Чебоксары [4]. У жительниц г. Москвы, имеющих менопаузу, был выявлен дефицит витамина D в крови в $70,3 \%$ случаев [11]. В Северо-Западном регионе России снижение концентрации витамина D до уровня недостатка и дефицита было установлено у $82,2 \%$ жителей в возрасте от 18 до 70 лет [7].

Целью работы явилось исследование содержания витамина D в сыворотке крови у лиц разных этнических групп, проживающих в Республике Бурятия.

\section{Материалы и методы}

Уровень витамина D - 25(OH)D в сыворотке крови был определен методом иммунохимиолюминесценции на аппарате Roche COBAS 6000 (Мангейм, Германия) у 1323 пациентов, направленных на обследование в клинико-диагностическую лабораторию Республиканской 
клинической больницы им. Н. А. Семашко врачами разных специальностей. Подавляющее большинство обследованных пациентов оказались жителями г. Улан-Удэ. Возраст пациентов составил от 20 до 86 лет. Согласно клиническим рекомендациям по диагностике, лечению и профилактике дефицита витамина D у взрослых 2016 г. дефицит витамина D определяется как уровень $25(\mathrm{OH}) \mathrm{D}$ в сыворотке крови менее 20 нг/мл. Содержание витамина D 20-30 нг/мл расценивается как недостаточность, за оптимальный уровень принято значение более 30 нг/мЛ [10].

\section{Результаты}

Всего проанализированы результаты анализов на содержание витамина D в сыворотке крови 1323 человек. Из них мужчин было 587 человек, женщин - 736.

Среднее содержание витамина D в сыворотке крови в общей группе обследованных пациентов составило 20,2 $\pm 11,3$ нг/мл, что свидетельствует о недостаточности витамина D в целом по группе.

Средняя концентрация витамина D в сыворотке крови у мужчин оказалась равной 23,6 13,3 нг/мл, что соответствует уровню, определяемому как недостаточность витамина D. У женщин уровень витамина D в сыворотке крови оказался соответствующим показателю дефицита и составил $18,6 \pm 9,8$ нг/мл.

Необходимо отметить, что в г. Улан-Удэ отмечается высокий уровень солнечной радиации, ежегодное число часов с солнцем очень высоко (более 2400 часов), по этому показателю город примерно соответствует таким южным городам России как Анапа и Находка. И, несмотря на это, содержание витамина D у жителей г. Улан-Удэ оказалось низким. При этом, мы не учитывали сезонность определения витамина D, часть пациентов была обследована в летнее время, когда дневные температуры позволяют носить открытую одежду. Большую часть года температурный фон не позволяет получать жителям Бурятии количество солнечного света, достаточное для синтеза витамина D кожей в необходимом количестве.

При разделении групп обследованных пациентов по расовой принадлежности были получены следующие результаты. Мужчин европеоидной расы оказалось 279, мужчин-азиат - 208 человек, женщин европейской национальности - 395, женщин-азиаток 341.

Среднее содержание витамина D в сыворотке крови у мужчиневропеоидов составило 25,2 $\pm 13,3$ нг/мл, что оказалось достоверно выше, чем у мужчин-азиат - 21,6 $\pm 12,7$ нг/мл.

Среднее содержание витамина D в сыворотке крови у женщин-

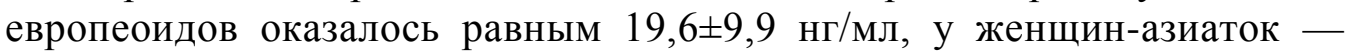
$16,6 \pm 9,1$ нг/мл, различия в показателях также оказались статистически достоверными $(\mathrm{p}<0,01)$. 
T. И. Батудаева, Д. 3. Санжиева. Витамин D как фактор риска остеопороза у населения Республики Бурятия

\section{Заключение}

Таким образом, результаты данного исследования свидетельствуют о том, что уровень витамина D y населения Республики Бурятия является низким, соответствующим недостаточности у мужского населения и дефицита - у женщин. Кроме того, низкий уровень витамина $\mathrm{D}$ может явиться одной из весомых причин развития остеопороза и связанных с ним переломов костей скелета, что, возможно, вносит свой вклад в различия в частоте остеопорозных переломов у жителей Бурятии разных этнических групп, т.е. более низкий уровень витамина D в сыворотке крови у лиц бурятской национальности возможно является одной из причин более высокой частоты малотравматичных переломов у коренного населения республики. Полученные результаты требуют дальнейшего изучения и подтверждения.

\section{Литература}

1. Батудаева Т. И. Клинико-эпидемиологические особенности осложнений остеопороза у жителей Республики Бурятия // Вестник РАЕН. 2014. T. 14(6). С. 97-101.

2. Батудаева Т. И., Меньшикова Л. В., Шегимова Е. А Анализ отдельных факторов риска остеопороза у женщин, проживающих в г. Улан-Удэ // Сиб. мед. журнал. 2010. № 6. С. 60-62.

3. Батудаева Т. И., Спасова Т. Е. Распространенность осложнений остеопороза у жителей г. Улан-Удэ // Acta Biomedica Scientifica. 2015. T. 2(102). C. 46-48.

4. Борисова Л. В., Петрова А. С. Содержание витамина D3 у практически здоровых лиц, проживающих в г. Чебоксары. В кн.: Сборник научных трудов, посвященных 55-летию ГУЗ «Республиканский эндокринологический диспансер». Чебоксары; 2011. С. 86-89.

5. Добровольская О. В., Торопцова Н. В., Лесняк О. М. Экономические аспекты осложненного остеопороза: стоимость лечения в течение первого года после перелома // Современная ревматология. 2016. Т. 10(3). С. 29-34.

6. Здоровье скелета: проблемы и пути решения. Глобальный план изменения ситуации [Электронный ресурс] / Available at: URL: http://share.iofbonehealth.org/WOD/2016/thematic-report/WOD16-report-WEBRU.pdf (дата обращения: 20.02.2019).

7. Распространенность дефицита витамина D в Северо-Западном регионе РФ среди жителей г. Санкт-Петербурга и г. Петрозаводска / Т. Л. Каронова, Е. Н. Гринева, И. Л. Никитина и соавт. // Остеопороз и остеопатии. 2013. № 3. C. $3-7$.

8. Лесняк О. М. Клинические рекомендации по профилактике и ведению больных с остеопорозом. Ярославль: Литера, 2012. 23 с.

9. Мельниченко Г. А., Белая Ж. Е., Рожинская Л. Я. и соавт. Федеральные клинические рекомендации по диагностике, лечению и профилактике остеопороза // Проблемы эндокринологии. 2017. Т. 63(6).

10. Пигарова Е. А., Рожинская Л. Я., Белая Ж. Е. и соавт. Клинические рекомендации Российской ассоциации эндокринологов по диагностике, 
лечению и профилактике дефицита витамина D у взрослых // Проблемы эндокринологии. 2016. Т. 62(4). С. 60-61.

11. Торопцова Н. В., Никитинская О. А., Беневоленская Л. И. Профилактика первичного остеопороза с помощью различных препаратов кальция // Остеопороз и остеопатии. 2005. № 1. С. 36-39.

12. Bischoff-Ferrari H. A., Willett W. C., Wong J. B., et al. Fracture prevention with vitamin D supplementation: a meta-analysis of randomized controlled trials // JAMA. 2005. T. 293. P. 2257-64.

13. Hernlund E., Svedbom A., Ivergard M., et al. Osteoporosis in the European Union: medical management, epidemiology and economic burden: A report prepared in collaboration with the International Osteoporosis Foundation (IOF) and the European Federation of Pharmaceutical Industry Associations (EFPIA) // Arch Osteoporos. Dec. 2013. T. 8(1-2). P. 136. 
T. И. Батудаева, Д. 3. Санжиева. Витамин D как фактор риска остеопороза у населения Республики Бурятия

\section{VITAMIN D AS A RISK FACTOR OF OSTEOPOROSIS IN THE POPULATION OF THE REPUBLIC OF BURYATIA}

\section{Tatiana I. Batudaeva}

Candidate of Medical Sciences, Associate Professor

Head of the Department of Therapy,

Medical Institute, Dorzhi Banzarov Buryat State University

36a, Oktyabrskaya st., Ulan-Ude, 670001, Russia

E-mail: batudaeva@gmail.com

\section{Dulma Z. Sanzhieva}

Doctor of the clinical diagnostic laboratory of the Republican Clinical Hospital named N. A. Semashko.

12, Pavlov st., Ulan-Ude, 670047, Russia

E-mail: sanzhieva.dulma@yandex.ru

We have determined the level of vitamin 25(OH)D in the blood serum of 1323 patients living in the Republic of Buryatia and compared it in relation to gender and race. The average serum vitamin $\mathrm{D}$ in men was $23.6 \pm 13.3$ $\mathrm{ng} / \mathrm{ml}$, indicating a low concentration of vitamin D. In women, the average vitamin D level was $18.6 \pm 9.8 \mathrm{ng} / \mathrm{ml}$ and corresponded to a deficiency. Analysis of the average concentration of vitamin D in blood serum in people of different races showed that men and women of the Asian race have significantly lower levels of vitamin D compared with people of the Caucasian race. Asian men had an average vitamin D concentration of $21.6 \pm 12.7 \mathrm{ng} / \mathrm{ml}$, European men $25.2 \pm 13.3 \mathrm{ng} / \mathrm{ml}$, Asian women $16.6 \pm 9.1 \mathrm{ng} / \mathrm{ml}$ and women European race $-19.6 \pm 9.9 \mathrm{ng} / \mathrm{ml}$, respectively $(\mathrm{p}<0.01)$.

Keywords: osteoporosis, risk factors, osteoporotic fractures, vitamin D. 